\title{
Legitimacy in an Era of Fragmentation: The Case of Global Climate Governance
}

\author{
Sylvia I. Karlsson-Vinkhuyzen and Jeffrey McGee*
}

Since 1992, the United Nations Framework Convention on Climate Change (UNFCCC) process has been widely viewed as the key international forum to discuss climate change. However, since the mid-2000s there has been a growing fragmentation in global climate governance through the creation of several climate change forums, such as the Asia-Pacific Partnership on Clean Development and Climate (APP), the Major Economies Meetings (MEM) and Forum (MEF) organized by the United States, as well as the novel use of existing forums, such as the G8. ${ }^{1}$ These forums are comprised of groups of between seven and seventeen countries and can be described as "minilateral" forums of climate dialogue. ${ }^{2}$ The formation of these minilateral forums occurred at a time in which the US had repudiated the Kyoto Protocol and was advocating for alternative approaches to global emission reduction. ${ }^{3}$

The emergence and operation of these minilateral climate change forums has received only scant academic attention. A reason for this could be that they are considered peripheral in global climate governance due to assumed low legitimacy, influence, and/or effectiveness. We argue that it is necessary to analyze these forums rigorously in order to understand their emergence and role. We therefore offer a systematic analysis of the normative legitimacy of these forums and put this in the context of the exercise of power.

Our analysis proceeds as follows. We first briefly discuss the relationship between legitimacy and power in international governance and outline a framework for evaluating the normative legitimacy of governance forums. Next, we describe the three minilateral forums we focus on: (1) the APP; (2) the G8; and (3) the MEM/MEF. This is followed by a discussion of our findings on their source-based, process-based, and outcome-based legitimacy. We then examine the power-legitimacy dynamics between minilateral forums and the UNFCCC,

\footnotetext{
* We gratefully acknowledge the valuable comments on earlier versions by Oran Young, Fariborz Zelli, Harro van Asselt, and two anonymous reviewers. We also thank the Earth System Governance project for providing several opportunities to present this paper.

1. Biermann et al. 2009.

2. Victor 2011; Eckersley 2012.

3. Hoffmann 2011.
} 
and demonstrate the value of looking beyond traditional notions of influence and effectiveness to understand the role minilateral forums have played in shaping global climate governance.

\section{Assessing Legitimacy and its Link to Power}

Academic researchers are interested in legitimacy as a factor for justifying the authority of international institutions and contributing to state compliance with international norms. ${ }^{4}$ Legitimacy, whether "normative" (i.e., based on normative theories of democracy or justice) or "sociological" (i.e., based on the views of those subject to the authority), ${ }^{5}$ is not static over time. For example, Clark describes international society "as a set of historically changing principles of legitimacy." 6 Power plays a particular role in the dynamics of sociological (and indirectly also normative) legitimacy. However, it is difficult to conceptualize the precise nature of this relationship, that is, whether the "generation of legitimacy is autonomous from the power relations that it 'legitimizes'" or whether "legitimacy is reduced to the preferences of those hegemonic forces that are thought to manufacture it in the first place." 7 Powerful actors engage in efforts to change what is considered legitimate in international society because legitimacy makes power more effective and its maintenance less costly.

This link between power and legitimacy in international society requires considerably more analysis, particularly linked to specific issue areas and institutional constellations. As a starting point, this requires a systematic analysis of the normative and/or sociological legitimacy across different settings. To facilitate such an analysis, Karlsson-Vinkhuyzen and Vihma ${ }^{8}$ have developed an analytical framework for evaluating normative legitimacy (see Table 1) based on the literature on normative legitimacy in international governance. ${ }^{9}$ We use this framework to compare the legitimacy of the three minilateral climate change forums with the UNFCCC, and thereby explain the reasons for the creation of these forums and their role in global climate governance. ${ }^{10}$ While the framework was developed for analyzing the legitimacy of different types of international norms, it can also be applied to governance forums, since the intended major outcomes of these forums are new norms, and the legitimacy of norms is closely linked to the legitimacy of the forums in which they are developed. ${ }^{11}$

Our interest in the dynamics between power and legitimacy in the frag-

4. Brunnée and Toope 2010.

5. Bodansky 1999.

6. Clark 2005, 7 .

7. Clark 2005, 20.

8. Karlsson-Vinkhuyzen and Vihma 2009.

9. Franck 1990, Bodansky 1999; Scharpf 1999; Scholte 2002; Zürn 2004.

10. See Van de Graaf article, this issue, for a power- and interest-based analysis of the creation of a new institution in the field of global energy governance, the International Renewable Energy Agency.

11. Franck 1990. 
Table 1

Components of Legitimacy of International Norms ${ }^{\mathrm{a}}$

\begin{tabular}{ll}
\hline Components of Legitimacy & Sub-Components \\
\hline Source-based legitimacy & Expertise \\
(input legitimacy) & Tradition \\
& Discourse \\
Process-based legitimacy & Governmental participation \\
(input legitimacy) & Non-governmental participation \\
& Accountability \\
& Transparency \\
Outcome-based legitimacy & Effectiveness \\
(output legitimacy) & Equity \\
\hline
\end{tabular}

aAdapted from Karlsson-Vinkhuyzen and Vihma 2009, 410.

mented field of global climate governance could arguably also be pursued using a framework based on sociological legitimacy. Developing such a framework would require extensive empirical investigation requiring access to key state stakeholders and an analysis of legitimating discourses. However, there is a strong connection between normative and sociological forms of legitimacy. ${ }^{12}$ Factors identified as sources of normative legitimacy are grounded in normative theories that reflect prevailing sociological standards in a society. Conversely, dominant normative theories of legitimacy influence what factors are considered relevant for sociological legitimacy. ${ }^{13}$ In this sense, a comprehensive analysis of normative legitimacy is a useful guide to prevailing sociological concepts of legitimacy.

Karlsson-Vinkhuyzen and Vihma's analytical framework of normative legitimacy builds on Bodansky's study of legitimacy, understood as justification of authority. ${ }^{14}$ Bodansky distinguishes three categories of legitimacy: (1) source of authority ( i.e., "source-based legitimacy"), (2) fairness of process in decision-making (i.e., "process-based legitimacy"), and (3) substantive value of the outcome (i.e., "outcome-based legitimacy"). This distinction partly overlaps with Scharpf's distinction between input and output legitimacy. ${ }^{15}$ For each of Bodansky's categories, the framework provides further sub-categories that allow for more refined analysis of normative claims of legitimacy. Below we elaborate on these sub-categories to enable qualitative judgments on the level of legitimacy of the minilateral climate change forums.

12. Black 2008.

13. Karlsson-Vinkhuyzen and Vihma 2009.

14. Bodansky 1999.

15. Scharpf 1999. 


\section{Source-Based Legitimacy}

There are at least three forms of source-based legitimacy. First, the progress of science and reliance on human rationality in governance has made expertise an important source of legitimacy. This is particularly so in environmental governance, where science helps identify problems, causes and a range of possible human responses. Second, institutions gain legitimacy through tradition, that is, by a significant history of addressing problems. Once tradition is established, an institution may become difficult to change as its longevity "pulls toward rule compliance by emphasizing the deep rootedness of the rule or the rule-making authority," thus conferring it with a pedigree that further enhances its legitimacy. ${ }^{16}$ Third, the extent to which the discourses propagated fit with the dominant discourses of society, reflecting particular normative principles (for example human rights), is another form of source-based legitimacy.

\section{Process-Based Legitimacy}

Procedural legitimacy concerns normative judgments about fairness in the process by which decisions are made. At the domestic level, process-based legitimacy is often associated with liberal democratic states, freedom of speech, transparency in government decision-making, and government accountability through open and fair elections. At the international level, equal participation of states (i.e., universal multilateralism) can be viewed as a manifestation of one of the key principles of democracy. ${ }^{17}$ However, many questions arise about what type of democracy is desirable or even possible in global governance. ${ }^{18}$ International norms are often found in treaties and institutions with a "one country one vote" rule where a state is not bound until it consents and, in many cases, obtains ratification from its parliament. This means that democratic legitimation of international treaty making could to a limited degree take place within the domestic political system of each country. ${ }^{19}$ However, to further improve "democratic" decision-making in global governance, complementary sources of process-based legitimacy have been explored, including participation by nongovernmental actors. ${ }^{20}$ Broader participation of state and non-state actors requires transparency in international decision-making processes, as these actors need access to information to effectively engage in decision-making. Finally, accountability is another source of process-based legitimacy in the international system. Mashaw describes accountability as having six basic elements: it is about whom is held answerable, "to whom, about what, through what processes, by what

16. Franck $1990,94$.

17. Archibugi 2004.

18. Bodansky 1999; Moravcsik 2004.

19. Karlsson-Vinkhuyzen and Vihma 2009.

20. Reinicke and Witte 2000; Scholte 2002. 
standards, and with what effect." ${ }^{21}$ In our case, accountability concerns the ability of states and other actors to hold other states to account for the contents of and the compliance with the norms those states develop.

\section{Outcome-Based Legitimacy}

The outcome-based (also referred to as substantive) legitimacy of international governance is first of all based on its effectiveness. There are a number of ways to measure the effectiveness of governance, for example: (1) the nature of the norms created by governance; (2) changes in actor behavior caused by governance; or (3) actual changes in the natural environment caused by governance. ${ }^{22}$ In assessing outcome-based legitimacy, we are ultimately interested in this third measure of effectiveness: the extent to which governance contributes to problem-solving. However, outcomes (i.e., the degree of behavioral change) usually contribute to impact effectiveness. The second indicator of outcomebased legitimacy is the degree to which the outputs of an institution are equitable in the sense of meeting principles of distributive justice. While there are competing versions of distributive justice-which, in turn, may lead to different findings about legitimacy - we adopt an international justice approach. This approach seeks to extend liberal justice principles to the international sphere ${ }^{23}$ and is a significant theme within normative analysis of international climate change policy. ${ }^{24}$

\section{Three Minilateral Climate Change Forums}

This section provides a more detailed description of the minilateral climate change forums introduced above.

\section{The Group of Eight}

The G8 is a forum of economically powerful nations, currently comprising Canada, France, Germany, Italy, Japan, Russia, the United Kingdom, and the US. Since the mid-1970s, heads of state of the G8 countries have met annually to discuss issues regarding the global economy. It is an informal forum that produces declarations and occasionally initiates short-term task forces to investigate particular issues. The G8 has no constitution, secretariat, or common communication tool, such as a website.

In 1989, the then G7 discussed climate change and strongly advocated common efforts to reduce greenhouse gas emissions and link the issue to energy

21. Mashaw 2006, 118.

22. Underdal 2002.

23. Okereke 2008.

24. Vanderheiden 2008. 
policy. ${ }^{25}$ Early G8 references to climate change were general and referred to the development of international law in other institutions, such as the UN. However, in 2005 UK Prime Minister Tony Blair moved climate change to the top of the G8 agenda for the Gleneagles Summit. The summit produced the G8 Communiqué on Climate Change, Energy and Sustainable Development, and a Plan of Action (PoA). ${ }^{26}$ The mitigation actions described in these documents were primarily aimed at making energy production and consumption less carbonintensive by promoting innovation, technology transfer, improving regulatory frameworks, and educating energy users. ${ }^{27}$ The Gleneagles summit set up "the Gleneagles Dialogue," which was designed to (1) transform domestic energy systems, (2) monitor implementation of the PoA, and (3) share best practices between participating governments. ${ }^{28}$ In 2006 the Russian presidency of the G8 focused on energy security rather than climate change. However, in 2007 Germany pushed the G8 for the first time to "consider seriously [ . . .] at least halving of global emissions by 2050," and to work toward this goal within the UNFCCC process. ${ }^{29}$

During 2008, the Japanese G8 presidency received a report from the Gleneagles Dialogue and maintained a focus on climate change. ${ }^{30}$ Japan launched a number of initiatives, such as collaboration with the International Energy Agency (IEA), and the creation of a new international partnership on energy efficiency. ${ }^{31}$ In G8 meetings in Italy (2009), Canada (2010), and France (2011), climate change was much lower on the agenda. The meeting in Italy strengthened commitment of industrializing states to an 80-percent reduction of greenhouse gas emissions, although the base year for reductions was unclear. For the Obama administration the G8 meetings (and MEF; see below) became arenas where world leaders could discuss the shape of post-2012 global climate governance. ${ }^{32}$

\title{
Asia-Pacific Partnership
}

The APP was launched in 2005 with six member countries: Australia, China, India, South Korea, Japan, and the US. These countries described the partnership as an "innovative and a fresh new development for the environment, energy security and for economic development in the region." 33 The APP vision statement contained broad references to intended cooperation but scant informa-

\author{
25. G8 1989. \\ 26. G8 2005a. \\ 27. G8 2005b. \\ 28. G8 2005b. \\ 29. G8 2007. \\ 30. Karlsson 2009. \\ 31. Lesage et al. 2010. \\ 32. Brunnée and Toope 2010. \\ 33. Downer 2005, 1.
}


tion on how the partnership would actually operate. ${ }^{34}$ Any goals set by APP countries would be voluntary and determined domestically. The 2006 APP Charter established the key governing body, the policy and implementation committee (PIC) comprised of governments, as well as eight industry-based task forces, with representatives from government, research organizations, and corporations. ${ }^{35}$ The task forces were to formulate plans for various projects on technology development and information sharing and were subject to approval and funding allocation from the PIC. ${ }^{36}$ By 2008, the APP had received only US $\$ 200$ million in public funding from the seven partner governments (Canada joined in 2007), with the private sector expected to provide significant funding for the implementation of APP projects. ${ }^{37}$ By 2009, the total number of approved projects was $175 .^{38}$ In April 2011, it was announced that the partnership would cease, with unfinished projects being transferred to other forums. ${ }^{39}$

\section{The Major Economies Meetings/Major Economies Forum}

In 2007, the US' George W. Bush administration announced the Major Economies Meeting (MEM), which became a series of US-sponsored meetings of the top fifteen emitting economies that were intended to "complement" the UN process. The MEM's purpose was to develop a long-term global goal to reduce greenhouse gas emissions, with each country to establish mid-term national targets and programs based on national circumstances. The MEM initiative proposed that its members develop national commitments to promote clean energy technologies, with the US prepared to facilitate international financial institutions providing low-cost financing for clean energy technology transfer. For the Bush administration, the MEM process was intended to build on and advance US relations with the APP and other technology and bilateral partnerships. ${ }^{40}$ The MEM adopted the APP approach of facilitating meetings of representatives from industry sectors such as power generation and energy production to devise a "common work program on best practices." 41

The MEM process concluded with a meeting following the 2008 G8 summit in Japan. This produced a declaration indicating that developed nations would implement economy-wide mid-term goals and actions to achieve absolute emission reductions, although those countries could also focus on "stopping the growth" of emissions rather than achieving absolute emission reductions. ${ }^{42}$

34. Asia-Pacific Partnership 2005.

35. Asia-Pacific Partnership 2006.

36. Asia-Pacific Partnership 2006.

37. US State Department 2008.

38. Asia-Pacific Partnership 2010.

39. Asia-Pacific Partnership 2011.

40. White House 2007a.

41. White House 2007b.

42. White House 2008. 
In March 2009, the Obama administration re-launched the MEM process as the Major Economies Forum on Energy and Climate (MEF). ${ }^{43}$ The seventeen countries of the MEF met on five occasions leading up to the fifteenth Conference of the Parties (COP-15) to the UNFCCC in Copenhagen. By July 2009, the MEF produced a declaration recognizing the need to mobilize extra investment in developing countries to address climate change. ${ }^{44}$ The MEF also established a "global partnership" to drive transformational low-carbon, climate-friendly technologies - with the goal of producing technology actions plans to share information across ten selected industries. ${ }^{45}$ However, the declaration lacked a long-term target for global emissions reduction or mid-term targets for individual countries. The MEM process was initially viewed by the EU as an attempt to compete with the UNFCCC discussions. ${ }^{46}$ Under Obama's leadership, however, the international community was less suspicious that the MEF meetings would marginalize the UNFCCC. ${ }^{47}$

\section{Source-Based Legitimacy of Minilateral Forums}

Applying the framework discussed above, the following sections examine the level of normative legitimacy of these minilateral climate change forums, and compare this to the normative legitimacy of the UNFCCC process.

\section{Expertise in the Background}

The UNFCCC has had close links with the Intergovernmental Panel on Climate Change (IPCC) since its inception, and has its own subsidiary body. While this strong institutional connection to scientific knowledge does not mean that this knowledge has been the key driver for decisions made in the UNFCCC process, it has given the climate change regime significant exposure to expertise. In contrast, the minilateral forums have generally not achieved significant sourcebased normative legitimacy through linking their decisions to existing expertise or to new knowledge commissioned for their use. One exception is the link between the G8 and the Stern Review on the economics of climate change. ${ }^{48}$ Prime Minister Blair commissioned the Stern Review during the UK's G8 presidency, as it was believed that the economics of climate change had not been sufficiently investigated by the IPCC. The results were first presented to the G8 Gleneagles Dialogue meeting in 2006 and influenced the public debate on climate action in many countries. Furthermore, the Gleneagles PoA involved the IEA and World Bank to carry out specific tasks, which could be seen as strengthening the

43. US State Department 2010.

44. Major Economies Forum 2009.

45. For a detailed comparison of the APP and MEM process, see McGee and Taplin 2009.

46. EU Observer 2007.

47. Brunnée and Toope 2010.

48. Stern 2007. 
G8's expertise-based legitimacy. To the extent these institutions can be considered sources of knowledge for energy policy, this contributes to their normative legitimacy.

In 2005, the Australian government used its own economic agency, the Australian Bureau of Agricultural and Resource Economics, to model the likely effectiveness of a global pledge and review architecture based on the APP. ${ }^{49}$ The government used the report to advocate for the APP as a possible design for global climate governance. However, the report highlighted the APP's lack of ambition on emission reduction, showing that even in the best-case scenario the partnership would still result in global greenhouse emissions doubling by $2050 .^{50}$ The report was generally viewed negatively by the media and NGOs and failed to significantly bolster the source-based legitimacy of the APP.

In short, the G8, APP, and MEM/MEF indirectly command the resources of the richest governments, but with a few exceptions these forums have not been used to build expertise-based normative legitimacy on climate change.

\section{Brief Tradition}

The G8 was created well before climate change emerged on the international policy agenda. However, like the APP and MEM/MEF, the G8 only started to seriously engage with climate change after 2005. At that time, the UNFCCC and Kyoto Protocol were already deeply institutionalized into a negotiation machinery of high complexity. Nonetheless, the Kyoto Protocol had only entered into force one year earlier, and the US and Australia arguably launched the APP as an effort to destabilize the Kyoto Protocol before it established a tradition as the main international institution on climate change. Similarly, the MEM was in part established by the Bush administration in 2007 to provide an alternative negotiating forum outside the UNFCCC..$^{51}$ The tradition of the three minilateral forums in dealing with international climate policy is thus too limited to substantially contribute to their normative legitimacy when contrasted with the UNFCCC.

\section{Discourse that Divides}

In contrast to the UNFCCC, where a majority of developing countries set the tone on equity and poverty eradication in the midst of various other discourses, the G8 has a strong track record of supporting one single discourse-a marketliberal discourse of globalization, trade liberalization, and privatization that has been dominant in international institutions over the last two decades. ${ }^{52}$ Normative judgments of source-based legitimacy therefore depend on the ideological

49. Fisher et al., 2006.

50. Fisher et al., 2006, 34.

51. Brunnée and Toope 2010.

52. Dryzek 2006. 
starting point adopted. If this is a market-liberal discourse, then the G8's support of the Washington consensus and the APP's business-friendly, growthoriented, bottom-up, technology-based approach to climate change mitigation contribute to their source-based legitimacy. However, if the starting point is one of equity, particularly international justice, the focus of the minilateral forums on climate mitigation while neglecting climate impacts, adaptation concerns, and the principle of common but differentiated responsibilities ${ }^{53}$ reduces their legitimacy.

To summarize, the minilateral forums studied in this article fare poorly on source-based legitimacy. They do not link clearly to existing or new scientific knowledge. Moreover, their history on climate change is brief and their dominant discourses do not score well from a perspective of international justice and equity.

\section{Process-Based Legitimacy of Minilateral Forums}

\section{Limited Government Participation}

The three minilateral forums are comprised of small groups of states, in contrast to the almost universal membership of the UNFCCC. The G8 is limited to eight of the world's largest economies, although it has taken steps to temporarily associate more countries with their meetings. For instance, the 2005 G8 Gleneagles Summit included China, India, Mexico, South Africa, and Brazil (the " +5 " countries), six African countries, the African Union, the IEA, the World Bank, and the International Monetary Fund. Subsequent G8 summits have also invited the " +5 " countries. However, this has not increased the representation of people most vulnerable to climate change, such as the small island developing states.

Participation in the APP was also limited to seven large economies. The APP was formed during negotiations in 2004 and 2005, initiated by the US and Australia. ${ }^{54}$ No information was released to the public during these negotiations. When initiating the MEM/MEF meetings, the US only invited the sixteen largest emitting countries (including the European Union).

All three minilateral forums were thus initiated by an exclusive group of economically powerful developed states who issued invitations only to the most powerful developing countries, invitations these countries were reluctant to decline despite their repeated statements in favor of the UNFCCC as the only legitimate climate negotiation forum. ${ }^{55}$ For the APP and MEM, the inclusion of large developing countries was a key reason for their creation. The APP

53. van Asselt 2007.

54. Sheridan 2006, 246-248.

55. McGee and Taplin 2009. 
and MEM provided arenas to draw such countries into discussions on climate mitigation while downplaying the increasingly controversial distinction between developed and developing countries entrenched in the UNFCCC and Kyoto Protocol.

\section{Restricted NGO Participation}

The UNFCCC has explicitly encouraged civil society participation in the form of lobbying and information transmission, ${ }^{56}$ and has institutionalized procedures for accrediting NGOs as observers with access to most meetings. As a result, thousands of observers attend the various meetings, enabling at least the most capable of them to have direct conversations with negotiators. It can thus be argued that a considerable number of NGOs find it worth the effort to spend resources on this lobbying activity, even though they have experienced frequent setbacks and their impact on the policy process is difficult to evaluate.

In contrast, the G8 has suffered ongoing criticism for a low level of interaction with civil society. During the late 1970s, "public recognition of civil society groups as interlocutors seems not to have entered the consciousness of the [then G7] leaders." ${ }^{57}$ By the late 1990s the G8 started to recognize civil society in its summit documents. From 1998 on, civil society grew in strength and sophistication with its lobbying tactics, and by the time of the 2005 Gleneagles Summit, alternative NGO summits, as well as large street demonstrations and other public events, were held in parallel with the official meeting. In terms of face-to-face interaction between civil society and officials-a minimal requirement for closer "participation" - the UK hosted a one-off meeting between almost all "sherpas" (personal representatives of G8 heads of state who prepare the meetings) and a sub-group of NGOs in 2005. One year later, Russia started the tradition of organizing a meeting between NGOs and all sherpas. Although difficult to evaluate, it is reasonable to expect that these brief one-off meetings are much less likely to exert influence than the multiple opportunities that NGOs have over an extended time period throughout the UNFCCC process.

The MEM/MEF have not invited NGOs or business groups to their meetings. ${ }^{58}$ Similarly, PIC meetings of the APP have only involved state actors. Business and research organizations were key participants in the APP industry task forces, but civil society NGOs were excluded from APP meetings across the board..$^{59}$

In summary, all three of the minilateral forums score low on this indicator of procedural legitimacy. In failing to give NGOs proper access to their meetings, the minilateral forums provide very limited opportunity for interaction with civil society, particularly when compared to the UNFCCC and its well insti-

56. McGregor 2011.

57. Hajnal 2007, 103.

58. Greenpeace 2008.

59. McGee and Taplin 2009. 
tutionalized procedures for enabling thousands of observers from a wide background to attend its meetings. A few largely symbolic attempts have been made by the G8 to meet with civil society, and the APP had business and research organization participants in its task forces but not in its key decisionmaking body.

\section{Low Transparency}

The UNFCCC process publishes all submissions by parties and observers, but interim negotiation documents are not always available to observers. While access to summit documentation was poor in the early years of the G7, each G8 presidency since the arrival of internet has placed the final documents on a summit webpage. The real discussion and negotiations take place during confidential preparation meetings of the G8 sherpas. ${ }^{60}$ The G8 has no tradition of producing reports on member states' implementation of earlier decisions. Nonetheless, the Gleneagles G8 Summit led to a formal three-year follow-up process to monitor the implementation of the PoA commitments. However, public information on this monitoring is limited. Public reports on the dialogue meetings have been brief, consisting of the chair's summary and interpretation of the proceedings. Actions by individual G8 member states are not reported.

Like the MEM, all meetings of the MEF between 2009 and 2011 were held behind closed doors and involved state actors only. The chair of each meeting produced a summary of the understandings reached that was posted on the MEF website, but these summaries give no indication of the positions of individual countries. APP ministerial meetings took a similar approach: a skeleton agenda of topics for discussion issued to the public beforehand and a broad communiqué issued thereafter. In addition, the APP released short statements from each country attending the ministerial meetings that very broadly outlined their positions. Moreover, there was no formal reporting on the proceedings of APP task force meetings.

The lack of openness of the G8, MEM/MEF, and APP meetings and limited reporting and verification of participant positions and actions suggests a transparency deficit, even if the UNFCCC process could also perform better in this regard.

\section{Accountability Problems}

The UNFCCC and Kyoto Protocol process have institutionalized reporting requirements from all parties, albeit with varying obligations as to detail and frequency for developed and developing states. This makes it possible for parliamentary bodies and the media in each state to comment upon the accuracy of 
reports and the degree (or lack) of implementation. The Kyoto Protocol also put in place a compliance mechanism that may hold parties accountable for lack of implementation of their obligations (e.g., for emission reductions or reporting).

The accountability of the minilateral forums may be approached from three perspectives. First, are participating states holding each other to account for the level of implementation of their earlier decisions? The G8 countries generally do not submit reports (public or private) on actions taken to implement decisions from previous summits. This is a reflection of a G8 culture of state-tostate congeniality and avoidance of criticism, as well as an eagerness of G8 hosts to focus on their "new" agenda rather than past decisions. While follow-up to the previous G8 summit is generally on the agenda of the sherpa meetings, there is no public information on the outcome.

The APP provided information on the basic cost and outcomes of task force projects. However, the APP made no effort to measure and verify the actions of individual countries, or to monitor compliance with self-imposed domestic goals. Similarly, the MEM/MEF meetings were high-level state-to-state arenas lacking mechanisms for measuring and verifying the very broad statements that countries made in their declarations. There thus seems to be very limited effort by the participating states to hold each other to account.

Second, what ability do citizens of participating states have to hold their governments to account for the decisions made at the forums? All three minilateral forums, particularly the MEM and the G8, are examples of foreign policy that is predominantly the prerogative of the executive branch of government. ${ }^{61}$ In the case of a closed meeting of heads of states as in the G8, the circle of people involved in negotiations and decision-making is an elite sub-group of the executive government. By contrast, many domestic constitutions require that treaties (e.g., the UNFCCC and Kyoto Protocol, although generally not COP decisions such as the Copenhagen Accord), are formally ratified through a parliamentary process before a state is bound by international law. This process provides an important venue for critical debate on a state's negotiation position, and can launch discussions on how the state intends to implement the agreement, including through the establishment of accountability mechanisms for its follow-up. By contrast, parliaments in G8 member countries generally have limited possibilities for holding their governments to account for policies adopted at G8 meetings; the same conclusion can be made for APP and MEM/MEF meetings.

Third, what level of accountability do the minilateral forums exhibit with regard to citizens of states not participating in the minilateral forums? G8 decisions may have significant impacts on citizens of countries that lie outside the borders of G8 countries, and may affect decision-making processes in other international forums. ${ }^{62}$ Civil society groups may protest and thus exert media 
pressure. Some international NGOs use a similar route of public accountability by monitoring G8 decisions and implementation and making their findings publicly available. For instance, a coalition of NGOs published report cards on the G8's compliance with its own environmental commitments. ${ }^{63}$ NGOs with high organizational and intellectual resources have the capacity to engage in such activities, but the smaller and less resourced ones do not. ${ }^{64}$ However, aside from social pressure in the global public sphere, there are no accountability mechanisms through which the global public affected by G8 decisions, or those of the APP and MEM/MEF, can hold the decision-makers to account.

In short, the G8, MEM/MEF, and APP include limited possibilities for creating accountability relationships along any of the three dimensions of accountability, particularly due to their low level of civil society participation and limited transparency.

\section{Outcome-Based Legitimacy of Minilateral Forums}

\section{Questionable Effectiveness}

The UN-based climate regime is not renowned for its effectiveness in terms of mitigation and adaptation action. High ambitions in long-term objectives are often matched with low ambitions in short-term specific commitments and implementation (e.g., emission reductions and finance). However, the Kyoto Protocol's emission reduction commitments are largely measurable and the degree of state compliance can be assessed. Measurement, reporting, and verification of emissions, as well as increasing the ambition of mitigation efforts, are issues high on the agenda of a future post-2020 climate agreement.

By contrast, the outcomes of the minilateral forums involve no binding targets, agreed baselines for emission reduction, or systems of formal reporting. This makes it very difficult to monitor the actions countries are purportedly taking to implement commitments, and thus the impact of such actions on alleviating climate change. Still, it is feasible to analyze the possible pathways of influence of the minilateral forums. Taking the G8 as the first example, it has the potential to influence three main categories of actors: member states, nonG8 states, and international organizations. Regarding the influence on its member states, an analysis of the degree of compliance with economic commitments from G7 communiqués between 1975 and 1989 estimated that G7 countries complied with only a third of their commitments. ${ }^{65}$ This does not fuel high expectations of compliance with climate change commitments. With respect to influencing other actors, the G8 commitments at Gleneagles in 2005 included some that were clearly targeted at other countries, but several also implicated in-

63. Hajnal 2007.

64. Orsini article, this issue.

65. Von Furstenberg and Daniels 1992. 
ternational actors, primarily the IEA and World Bank, or multilateral partnerships. ${ }^{66}$ The 25 energy efficiency policy recommendations adopted at Hokkaido in 2008 were accompanied by follow-up reporting and intended to influence countries beyond the G8. One potentially valuable innovation in the G8 approach, compared to that of the UNFCCC, has been a more direct focus on energy policy.

For the APP, information on its effectiveness in achieving its modest ambition on emission reductions is sketchy. As discussed above, an Australian government report suggested in 2006 that an APP-style institution adopted globally would still allow global emissions to double by 2050 compared to 2005 levels. ${ }^{67}$ The 2009 MEF Leaders Declaration recognized the "scientific view that the increase in global average temperature above pre-industrial levels ought not to exceed 2 degrees C." ${ }^{68}$ However, like the earlier outcome from the MEM under the Bush administration, it deferred setting specific measurable targets or commitments to achieve reductions in emissions.

The minilateral forums thus do not have much to show for effectiveness either in terms of ambition or in terms of results. It cannot be excluded that they have led to climate benefits, for example through their efforts to improve energy efficiency policies or by involving specific business sectors, but their lack of transparency makes it impossible to judge.

\section{Equity Marginalized}

International theories of justice seek to extend to the international sphere the liberal egalitarian concerns for ensuring the condition and liberties of the least advantaged in society. ${ }^{69}$ At a formal level, the UNFCCC process has some consistency with international justice principles in the concern shown by developed countries to lead in reducing emissions and provide financial resources for developing country compliance, adaptation, and technology transfer. At a practical level, the actions of developed countries have so far fallen well short of such leadership. However, at least formally, the distributive justice of the UNFCCC and Kyoto Protocol, based on the principle of common but differentiated responsibilities and its differentiation between developed and developing countries, is significantly weighted toward the less advantaged countries.

The minilateral forums have shown less concern for these matters. The G8's market-liberal economic agenda may rather aggravate disparities in NorthSouth economic development. The outcomes of the APP and MEM meetings departed from the principle of common but differentiated responsibilities by weakening the idea of formally differentiating between developed and developing countries in deciding on levels of emission reduction. The documents pro-

66. G8 2005b.

67. Fisher et al 2006, 34.

68. Major Economies Forum 2009.

69. Vanderheiden 2008, 53-54. 
duced by the minilateral forums have an overriding focus on mitigation rather than adaptation, reflecting the absence of the concerns of the poor and vulnerable countries in these forums. If this focus had led to ambitious mitigation efforts, there would be less need for adaptation. However, the minilateral forums have largely failed to deliver on both fronts, meaning the neglect of adaptation is difficult to justify.

When assessed on sourced-based, process-based, and outcome-based legitimacy, the three minilateral forums scored relatively low compared to the UNFCCC. The minilateral forums may bolster their low process-based legitimacy with increased outcome-based legitimacy by, for example, setting ambitious mitigation goals and internalizing the core principle of the UNFCCC regime on common but differentiated responsibilities. However, so far the minilateral forums have not realized this possibility.

\section{The Power-Legitimacy Dynamic between Minilateral and Multilateral Forums}

As discussed above, normative legitimacy is closely linked with sociological legitimacy in a given society. Sociological legitimacy is an important source of influence in the international society of states with its reliance on non-coercive means of compelling compliance with norms and standards of behavior. However, legitimacy both restrains power and is shaped by power in international society. It is important to note that while minilateral climate change forums were initiated by powerful northern states (e.g., the UK and the US), developing countries such as China and India, which had argued for the UNFCCC as the legitimate home of global climate negotiations, still accepted invitations to attend. It appears they wanted to avoid being excluded from high-level climate change talks involving key developed states and were also keen to see what they could gain from such alternative forums. ${ }^{70}$ Although they performed poorly on sourcebased, process-based, and outcome-based legitimacy, we argue that the minilateral forums still exerted an important discursive influence on the process and outcomes of the UNFCCC. This is the case because minilateral forums offered a site for powerful states, outside the UNFCCC process, to advocate for and contest ideas on the future of global climate governance.

\section{Influence on the UNFCCC Process}

The UNFCCC and Kyoto Protocol have developed through multilateral negotiations among most states and follow the traditional UN-based consensus negotiations. In practice, however, there are several dimensions of these negotiations that reduce their universality and introduce elements of small group discussion: (1) negotiations occur through negotiating blocks of states, such as the EU and

70. McGee and Taplin 2009. See also Van de Graaf article, this issue. 
the G77, which hide dissenting views; (2) developing countries often have small delegations present at the negotiations, thereby limiting participation and the universality of the decisions; (3) the UNFCCC has repeatedly authorized small groups of states, often referred to as "friends of the chair," to work out a final compromise and present it to the parties for adoption when deadlines are imminent.

However, these small group discussions within the UNFCCC process did not significantly reduce its legitimacy for the weaker states. This changed to some extent in the post-2012 UNFCCC negotiations, when the universality and transparency of the negotiation process was repeatedly questioned by some developing countries. Particularly, at COP-15 in Copenhagen it became clear that the host country (Denmark) had negotiated in secret with mostly developed and a few developing countries, producing an alternative text in parallel to the negotiations involving all parties. This caused an outcry from the G-77 and made it impossible for the presidency to establish a "friends of the chair" group..$^{71}$ Instead, the result from COP-15, the Copenhagen Accord, was crafted in the final hours by the US together with a small group of countries (26 at first, but later only five: Brazil, China, India, South Africa, and the US) in a process that had not been approved by the other parties. When this text was brought back into the COP, critical voices arose about the lack of proper process and several G77 member countries, including Bolivia, Cuba, Sudan, and Venezuela, prevented the accord from becoming a COP decision. ${ }^{72}$

We argue that the minilateral climate change forums outside the UNFCCC were an important step in developing and piloting the exclusive minilateral procedural norm that gained traction in Copenhagen. In the years leading to Copenhagen, the APP, G8, and MEM were the prime sites to develop acceptance of a process for exclusive high-level discussions on international climate policy in a small group of powerful developed and developing states. In the crisis atmosphere and stalemate of Copenhagen, after two years of extremely slow negotiations, the ground was fertile for powerful states to seek to salvage the meeting by adopting a strong minilateral process outside normal procedures.

\section{Influence on Multilateral Outcomes}

The past decade has seen ongoing contestation over the general architecture for global climate governance, including its legal form. The contestation over architecture concerns whether the future climate regime should be based on the Kyoto Protocol design of binding targets and timetables for emission reductions or instead a pledge and review design where each country sets its own targets (legally binding or not). Since the 2005 COP in Montréal the UNFCCC included negotiations on what should happen after the first commitment period 
of the Kyoto Protocol expired in 2012. After the 2007 COP in Bali, the negotiations among all UNFCCC parties included the type and legal form of mitigation commitments of both developed and developing countries.

The developed countries that were opposed to the binding targets and timetable design of Kyoto (primarily Australia, Canada, and Japan, and the US) opened a dialogue on alternative post-2012 architectures at the minilateral climate change forums outside the UNFCCC. The minilateral climate change forums, despite shortcomings in both normative legitimacy (according to our analysis) and sociological legitimacy in the eyes of many states and other observers, served as important sites for powerful states to build support for nonlegally binding and thus more voluntary norms than in the Kyoto Protocol in the post-2012 period. This echoes the argument of Zürn and Faude that fragmentation can increase the opportunities for strategic action. ${ }^{73}$ Particularly during the George W. Bush administration, the US advocated strongly for a voluntary pledge and review design for any global post-2012 climate agreement as piloted at a regional level through formation of the APP. ${ }^{74}$ In the MEM process, the US used the APP as an example of an institutional design for emission reductions that could be scaled up. ${ }^{75}$ Japan also actively distanced itself from the Kyoto model and advocated the APP model as an alternative architecture for future climate governance. ${ }^{76}$ The APP and MEM were thus used by key developed states to advocate and build support for a norm of voluntarism and thus a weaker legal form in the design of any post-2012 climate agreement.

At Copenhagen, the international community effectively put on hold its support for a legally binding architecture with specific obligations and clear compliance procedures that are the Kyoto Protocol's foundation. The Copenhagen Accord is based on the voluntary pledge-and-review architecture advocated by the US through the APP and MEM processes. The norm of voluntarism previously resisted in the UNFCCC by key developing countries was accepted in Copenhagen. This voluntarism was also intended to apply equally to developed and developing countries. The APP and MEM meetings had not only been important forums to advocate and experiment with the norm of voluntarism in global climate governance, but also served as arenas for bringing developed and developing countries into an institutional trajectory different from the binding targets and timetables model of the Kyoto Protocol. This was important because developed countries were hoping to draw large developing countries into commitments on emission reductions for the post-2012 period. The COP ultimately accepted this norm of voluntarism by formally endorsing the accord a year later in Cancún.

Agreement at the 2011 COP in Durban included an extension of the Kyoto

73. Zürn and Faude article, this issue.

74. See Van de Graaf article, this issue, for a different case (that of German leadership in establishing a new international institution on renewable energy).

75. White House 2007b.

76. Vihma 2009. 
Protocol to a second commitment period as a temporary arrangement for a limited set of developed country parties, plus a decision to negotiate a post-2020 agreement "with legal force" for all parties by $2015 .{ }^{77}$ However, there is significant ambiguity about what this phrase ultimately means, and there still is clear resistance to a legally binding agreement for all parties from key countries such as India.

In short, the legitimacy deficits identified in our analysis of the minilateral forums were no barrier to their role in discursive contestation over the architecture of international climate governance. Indeed, this shows how power can still trump and shape legitimacy. A better understanding of the circumstances under which this may be more likely to happen in fragmentation processes could be supported by more theory-driven explanations of the causes and consequences of fragmentation. ${ }^{78}$

\section{Conclusion}

Our analysis shows serious deficits in the source-based, process-based, and outcome-based legitimacy of the three minilateral forums when compared to the UNFCCC, even if the latter has its own conspicuous challenges on several components of legitimacy. The limited state participation, disconnect from civil society, and lack of transparency in the decision-making process in the minilateral forums weaken the accountability relationships toward both other states and the global public. The lower emphasis on substantive equity and concerns for the poor and vulnerable, reflected by low ambition on mitigation, weakening of the principle of common but differentiated responsibilities, and lack of attention to adaptation, give these forums very limited justification for their authority in influencing the process and outcome of global climate governance.

These findings, based on normative components of legitimacy, are echoed in the legitimacy judgments of non-governmental actors and some participants of these minilateral forums. There has been strong criticism of the minilateral climate forums from civil society representatives and less powerful states. Despite our findings that the minilateral forums have low normative legitimacy and indications of their low sociological legitimacy, they still appear to have exercised significant influence over global climate governance. This came about by powerful countries using the minilateral forums to advocate a discourse supporting a more exclusive negotiation process and voluntary approach to mitigation commitments that appears to have flowed back into the UNFCCC process. The fragmentation of global climate governance through minilateral forums is thus an important example of a contestation over legitimacy and power in international governance.

77. UNFCCC 2011a; UNFCCC 2011b.

78. Cf. Zelli and van Asselt article, this issue. 


\section{References}

Archibugi, Daniele. 2004. Cosmopolitan Democracy and its Critics: A Review. European Journal of International Relations 10 (3): 437-473.

Asia-Pacific Partnership. 2005. Vision Statement of Australia, China, India, Japan, the Republic of Korea, and the United States of America for a New Asia-Pacific Partnership on Clean Development and Climate.

2006. Charter.

. 2010. Project Roster.

- 2011. Asia-Pacific Partnership on Clean Development and Climate.

Bayne, Nicholas. 2004. Hard and Soft Law in International Institutions: Complements Not Alternatives. In Hard Choices, Soft Law: Voluntary Standards in Global Trade, Environment and Social Governance, edited by John J Kirton and Michael J Trebilcock, 347-352. Aldershot: Ashgate.

Biermann, Frank, Philipp Pattberg, Harro van Asselt, and Fariborz Zelli. 2009. The Fragmentation of Global Governance Architectures: A Framework for Analysis. Global Environmental Politics 9 (4): 14-40.

Black, Julia. 2008. Constructing and Contesting Legitimacy and Accountability in Polycentric Regulatory Regimes. Regulation \& Governance 2 (2): 137-164.

Bodansky, Daniel. 1999. The Legitimacy of International Governance: A Coming Challenge for International Environment Law? American Journal of International Law 93 (3): 596-624.

Brunnée, Jutta, and Stephen J. Toope. 2010. Legitimacy and Legality in International Law: An Interactional Account. Cambridge, UK: Cambridge University Press.

Clark, Ian. 2005. Legitimacy in International Society. New York: Oxford University Press.

Downer, Alexander. 2005. Press Conference: ITECC, Vientiane, Laos (28 July 2005). Available at http://pandora.nla.gov.au/pan/25167/20060602-0000/www .foreignminister.gov.au/transcripts/2005/050728_vientiane.html, accessed February 15, 2013.

Dryzek, John S. 2006. Deliberative Global Politics. Cambridge, UK: Polity Press.

Eckersley, Robyn. 2012. Moving Forward in the Climate Negotiations; Multilateralism or Minilateralism? Global Environmental Politics 12 (2): 24-42.

EU Observer. 2007. EU and US at Loggerheads over Climate Change (December 14, 2007). Available at http://euobserver.com/9/25338, accessed February 15, 2013.

Fisher, Brian, Melanie Ford, Guy Jakeman, Andrew Gurney, Jammie Penm, Anna Matysek and Don Gunesekera, 2006. Technological Development and Economic Growth. ABARE Research Report 06.1. Australian Bureau of Agricultural and Resource Economics: Canberra.

Franck, Thomas M. 1990. The Power of Legitimacy among Nations. Oxford, UK: Oxford University Press.

G8. 1989. Economic Declaration. Available at http://www.g8.utoronto.ca/summit/ 1989paris/communique/index.html, accessed February 15, 2013. . 2005a. Gleneagles Plan of Action: Climate Change, Clean Energy and Sustainable Development. Available at https://www.gov.uk/government/uploads/system/ uploads/attachment_data/file/48584/gleneagles-planofaction.pdf, accessed February 15, 2013. 
2005b. The Gleneagles Communiqué. Available at http://www.g7.utoronto.ca/ summit/2005gleneagles/communique.pdf, accessed February 15, 2013.

. 2007. Chair's Summary, Heligendamm, 8 June 2007. Available at http://www .g-8.de/Webs/G8/EN/G8Summit/SummitDocuments/summit-documents.html, accessed February 15, 2013.

Greenpeace. 2008. Bush Major Emitters Meetings: The Wrong Way on Climate Change, Greenpeace Briefing (January 2008). Available at http://www.greenpeace.org/ international/Global/international/planet-2/report/2008/1/bush-mem.pdf, accessed February 15, 2013.

Hajnal, Peter I. 2007. The G8 System and the G20. Evolution, Role and Documentation. Aldershot: Ashgate.

Hoffmann, Matthew. 2011. Climate Governance at the Crossroads: Experimenting with a Global Response after Kyoto. New York: Oxford University Press.

Karlsson, Sylvia I. 2009. G8 Climate Action from Gleneagles to Hokkaido-Dying Flare or Lasting Flame? Unpublished paper presented at the Annual Meeting of the International Studies Association, New York.

Karlsson-Vinkhuyzen, Sylvia I, and Antto Vihma. 2009. Comparing the Legitimacy and Effectiveness of Global Hard and Soft Law: An Analytical Framework. Regulation \& Governance 3 (4): 400-420.

Lesage, Dries, Thijs Van de Graaf, and Kirsten Westphal. 2010. Global Energy Governance in a Multipolar World. Farnham: Ashgate.

Major Economies Forum. 2009. Major Economies Meetings on Energy and Climate: The First Leaders Meeting. Available at http://www.majoreconomiesforum.org/pastmeetings/the-first-leaders-representatives-meeting.html, accessed February 15, 2013.

Mashaw, Jerry Louis. 2006. Accountability and Institutional Design: Some Thoughts on the Grammar of Governance. In Public Accountability: Designs, Dilemmas and Experiences, edited by Michael Dowdle, 115-156. Cambridge, UK: Cambridge University Press.

McGee, Jeffrey, and Ros Taplin. 2009. The Role of the Asia-Pacific Partnership in Discursive Contestation of the International Climate Regime. International Environmental Agreements: Politics, Law and Economics 9 (3): 213-238.

McGregor, Ian M. 2011. Disenfranchisement of Countries and Civil Society at COP-15 in Copenhagen. Global Environmental Politics 11 (1): 1-7.

Meilstrup, Per. 2010. The Runaway Summit: The Background Story of the Presidency of COP-15, the UN Climate Change Conference. In Danish Foreign Policy Yearbook 2010, edited by Nanna Hvidt and Hans Mouritzen, 112-136. Copenhagen: Danish Institute for International Studies.

Moravcsik, Andrew. 2004. Is There a 'Democratic Deficit' in World Politics? A Framework for Analysis. Government and Opposition 39 (2): 336-363.

Okereke, Chukwumerije. 2008. Global Justice and Neoliberal Environmental Governance: Ethics, Sustainable Development and International Co-Operation. New York: Routledge.

Reinicke, Wolfgang H., and Jan Martin Witte. 2000. Interdependence, Globalization, and Sovereignty: The Role of Non-Binding International Legal Accords. In Commitment 
and Compliance: The Role of Non-Binding Norms in the International Legal System, edited by Dinah Shelton, 75-100. Oxford, UK: Oxford University Press.

Scharpf, Fritz W. 1999. Governing in Europe: Effective and Democratic? New York: Oxford University Press.

Scholte, Jan Aart. 2002. Civil Society and Democracy in Global Governance. Global Governance 8 (3): 281-304.

Sheridan, Gregory. 2006. The Partnership: The Inside Story of the US-Australian Alliance under Bush. Sydney: UNSW Press.

Stern, Nicholas. 2007. The Economics of Climate Change: The Stern Review. Cambridge, UK: Cambridge University Press.

Underdal, Arild. 2002. One Question, Two Answers. In Environmental Regime Effectiveness: Confronting Theory with Evidence, edited by Edward L. Miles, Arild Underdal, Steinar Andresen, Jørgen Wettestad, Jon Birger Skjærseth, and Elaine M. Carlin, 345. Cambridge, MA: MIT Press.

UNFCCC. 2011a. Report of the Conference of the Parties of the UNFCCC on Its Seventeenth Session, Held in Durban from 28 November to 11 December 2011. Bonn: UNFCCC. Available at http://unfccc.int/resource/docs/2011/cop17/eng/09a01.pdf, accessed February 15, 2013.

2011b. Report of the Conference of the Parties of the UNFCCC and the Report of the Conference of the Parties Serving as the Meeting of the Parties to the Kyoto Protocol on Its Seventh Session, Held in Durban from 28 November to 11 December 2011. Bonn: UNFCCC. Available at http://unfccc.int/resource/docs/2011/ cmp7/eng/10a01.pdf, accessed February 28, 2013.

US State Department. 2008. US Involvement in the Asia-Pacific Partnership on Clean Development and Climate. Available at http://orbenergy.com/wp-content/uploads/ 2012/01/11_2008_Orb-profiled-in-APP-annual-report-p23.pdf, accessed February $15,2013$.

- 2010. Major Economies Forum on Energy and Climate. Available at http:// www.state.gov/e/oes/climate/mem/index.htm, accessed February 15, 2013.

van Asselt, Harro. 2007. From UN-ity to Diversity? The UNFCCC, the Asia-Pacific Partnership, and the Future of International Law on Climate Change. Carbon and Climate Law Review 1 (1): 17-28.

Vanderheiden, Steve. 2008. Atmospheric Justice: A Political Theory of Climate Change. New York: Oxford University Press.

Victor, David G. 2011. Global Warming Gridlock: Creating More Effective Strategies for Protecting the Planet. Cambridge, UK: Cambridge University Press.

Vihma, Antto. 2009. Friendly Neighbor or Trojan Horse? Assessing the Interaction of Soft Law Initiatives and the Un Climate Regime. International Environmental Agreements: Politics, Law and Economics 9 (3): 239-262.

Von Furstenberg, George M., and Joseph P. Daniels. 1992. Can You Trust G-7 Promises? International Economic Insights 3 (September/October): 24-27.

White House. 2007a. Fact Sheet: A New International Climate Change Framework (31 May 2007). Available at http://georgewbush-whitehouse.archives.gov/news/ releases/2007/05/20070531-13.html, accessed February 15, 2013.

. 2007b. Press Briefing by Tony Snow and Jim Connaughton, Chairman of the Council on Environmental Quality (31 May 2007). Available at http:// 
georgewbush-whitehouse.archives.gov/news/releases/2007/05/20070531-17.html, accessed February 15, 2013.

. 2008. Declaration of Leaders Meeting on Energy Security and Climate Change (9 July 2008). Available at http://georgewbush-whitehouse.archives.gov/news/ releases/2008/07/20080709-5.html, accessed February 15, 2013.

Zürn, Michael. 2004. Global Governance and Legitimacy Problems. Government and Opposition 39 (2): 260-287. 